\title{
Tales of the expected: investigating the rhetorical strategies of innovation champions
}

This is a pre-print version of the article: Leiringer, R. and Cardellino, P. (2008).

Tales of the expected: investigating the rhetorical strategies of innovation champions. Construction Management and Economics, 26(10), 1043-1054. DOI:10.1080/01446190802389394

The article is available at: http://www.tandfonline.com.eproxy1.lib.hku.hk/doi/pdf/10.1080/0144619080238 $\underline{9394}$ 


\begin{abstract}
Innovation continues to be high on the agenda in construction. It is widely considered to be an essential pre-requisite of improved performance both for the sector at large and for individual firms. Success stories dominate the parts of the academic literature that rely heavily on the recollections of key individuals. A complementary interpretation focuses on the way innovation champions in hindsight interpret, justify and legitimise the diffusion of innovations. Emphasis is put on the temporal dimension of interpretation and how this links to rhetorical strategies and impression management tactics. Rhetorical theories are drawn upon to analyse the accounts given by innovation champions in seven facilities management organisations. In particular, the three persuasive appeals in classic rhetoric are used to highlight the rhetorical justifications mobilised in the descriptions of what took place. The findings demonstrate the usefulness of rhetorical theories in complementing studies of innovation.
\end{abstract}

Keywords: Innovation, innovation champion, rhetorical strategies, impression management, legitimacy 


\section{Introduction}

Reviews of innovation literature have consistently revealed that it exhibits proinnovation bias (e.g. Abrahamson, 1991; Wolfe, 1994; Anderson et al. 2004). Whilst such claims at first might seem puzzling, they are not to be equated with the refutation of the importance of innovation. On the contrary, few other issues are characterised by such an overwhelming agreement within the academic community as the importance of innovation for technological and societal development. What these critics claim is that the universal acceptance of the importance of innovation influences the assumptions that form the basis of investigations on the topic. Several forceful arguments have accordingly been made for the introduction and increased use of multiple methodological perspectives in innovation research (e.g. Poole and Van de Ven, 1989; Abrahamson, 1991; Wolfe, 1994; O’Neill et al. 1998; Anderson et al., 2004).

Innovations are seldom fully observed and documented at their source. The practicalities of attaining long-term access and resourcing the required longitudinal fieldwork restrict the kinds of investigations necessary to achieve such documentation. A few notable exceptions do exist (e.g. Van de Ven et al., 1999), but these are almost exclusively found outside the construction-related literature. In consequence, publications within the construction domain that target the diffusion of specific innovations are predominantly based on ex post investigations reconstructing the facts and events that led up to the implementation and diffusion 
(e.g. Nam and Tatum, 1997; Ivory, 2005; Peansupap and Walker, 2006). This paper introduces a rhetorical perspective into innovation research in the construction management (CM) domain and attempts to demonstrate its utility in complementing commonly used research strategies. It takes as its starting point the increasing reliance on interviews in qualitative CM research (cf. Dainty, 2007); a trend which is also emerging in research targeting innovation in construction (e.g. Whyte, 2003; Briscoe, 2004; Mudrak et. al. 2005). Although it is widely known that a variety of variables influence interview outcomes, significant importance is consistently given to post hoc accounts from key individuals (e.g. Ivory, 2005; Peansupap and Walker, 2006; Gray and Davies, 2007; Widén and Hansson, 2007). The aim of this paper is to explore whether rhetorical perspectives can be used effectively to strengthen studies on innovation. In particular if attending to how key informants frame their accounts using rhetorical sequences would benefit research strategies that are based on ex post interviews.

The paper begins by highlighting the important role of the innovation champion in innovation diffusion, emphasising their prolonged responsibility that stretches beyond the conception and implementation of the innovation. Attention is then turned to impression management and how such tactics may play out in the research interview. Drawing on institutional and rhetorical theories of change the three common persuasive appeals in classic rhetoric are used to analyse the interview transcripts from a study conducted within the facilities management sector. Particular attention is given to how rhetorical strategies are used by innovation 
champions in their accounts of how specific FM innovations were initiated, adopted and diffused. The concluding discussions highlight the fashion and extent to which the innovation champions use rhetorical strategies when framing their accounts of innovation.

\section{The innovation champion as a key informant}

Most studies of innovation would, as part of their data gathering, strive to survey a variety of respondents. In studies of specific innovations it is common practice to elicit the views of respondents who have been identified as instrumental for the development of the innovation. The most prominent of these key respondents is the so called 'innovation champion'. It is generally accepted that the role played by this individual is pivotal to the success of the innovation endeavour (cf. Howell and Higgins, 1990; Sharma, 1999). A multitude of studies have found strong support for innovation success being closely linked with the presence of a champion (ibid). Construction is no exception. Winch (1998), for example, concludes that the most consistent finding from research on innovation is that innovation needs champions. Several other well cited publications on construction innovation confirm the importance of innovation champions (e.g. Tatum, 1984; Slaughter, 1998; Barlow 2000). This has led to reinforce the importance of the innovation champion as a key informant in research endeavours. 
Frequently the individuals identified as champions have senior managerial positions in the organisation (cf. Nam and Tatum, 1997; Dulaimi et al., 2005). Yet, innovations can take a myriad of forms and the position held by the innovation champion and the expertise and personal characteristics required therefore vary. It goes without saying that individuals championing a technological innovation need a degree of technological competence (cf. Nam and Tatum, 1997). Nevertheless, even in the pure engineering based scenario the innovation champion would not be able to rely on technological competence alone (cf. Akrich et al., 2002). To the contrary, much of the literature highlights the capacity to influence their surroundings as the most important characteristic of the innovation champion. Howell and Higgins (1990, p.320) provide the following synthesis:

“The literature on champions and innovation highlights the capacity of champions to inspire and enthuse others with their vision of the potential of an innovation, to persist in promoting their vision despite strong opposition, to show extraordinary confidence in themselves and their mission, and to gain the commitment of others to support the innovation."

It follows that any appointed (or self-appointed) champion of innovation would have to act out the acquired role across organisational boundaries. Managers 'championing' the adoption of new practices and technologies rationalise and legitimise their adoption and the subsequent use to different audiences (cf. Pfeffer, 1981; Elsbach, 1994; Suchman, 1995). These managers serve a significant function 
in the organisation by interpreting events and using those interpretations to frame meaning for other organisational participants (cf. Isabella, 1990; Ginzel et al., 2004). In short, what they say and how they say it matters a great deal for the diffusion of the innovations. However, their championing role does not stop there. Managers play an equally important role in conveying their organisation's ability to implement new strategies, structures and processes to its many external stakeholders (Rouleau, 2005; Fiss and Zajac, 2006). This responsibility, invariably, comes at the price of exposure and brings with it an added emphasis on performance that reflects both strategic operational challenges and institutional pressures. In consequence, cognitive and social bias towards confirmation of success has powerful reinforcing effects on how they portray their own work (cf. Salancik and Meindl, 1984; Ashforth and Gibbs, 1990; Strang and Macy, 2001). This bias towards confirmation of success is further enhanced by the temporal dimension of interpretation (cf. Isabella, 1990). The attribution of meaning and the significance given to specific events and actions vary over time (Ginzel et al., 2004). In combination with the inherent ambiguity surrounding causes and meanings of action this allows for an interpretation of events in a manner commensurate with self-interests. In hindsight managers might, therefore, reinterpret what were the results of selection pressures as conscious calculations and end up with an effectively designed strategy (Macy, 1997).

It follows from the above that the stated intrinsic merits of the innovation will have an objective and subjective dimension. Or put slightly differently, however 
instrumental the innovation appears its performance will still have a rhetorical and a substantive aspect to it (cf. Nelson et al., 2004). With this in mind, studies that rely on key respondents' recollection and interpretation of elapsed actions and events would benefit from looking more closely at how the described actions are justified and legitimised. In particular if the interpretations offered could be considered to be the result of impression management strategies.

\section{Impression management}

Impression management is commonly used to refer to behaviour that has the purpose of controlling or manipulating the attributions and impressions of others by controlling the information that is presented to them (Arndt and Bigelow, 2000). Wayne and Liden (1995, p.232) define impression management as 'those behaviours individuals employ to protect their self-images, influence the way they are perceived by significant others, or both'. Whilst originating from social psychology impression management studies have become increasingly common in management research (cf. Wayne and Liden, 1995; Bozeman and Kacmar, 1997). Studies have been undertaken of organisational behaviour on the individual level as well as organisational responses to various events (e.g. Gilmore and Ferris, 1989; Elsbach, 1994). In general terms, the former focuses on the interview situation whilst the latter focuses on attempts to gain or sustain organisational legitimacy in the marketplace. 
Impression management does not necessarily entail pretence or deceit; rather it could be viewed as a ubiquitous element of social behaviour. It revolves around the conscious, or unconscious, packaging of information such that it leads target audiences to desired conclusions (Staw et al., 1983; Salancik and Meindl, 1984; Gardner and Avolio, 1998). Behaviours associated with impression management include the use of verbal statements, nonverbal or expressive behaviours, integrated behaviour patterns (such as the performance of favours) and alteration of physical appearance (Wayne and Liden, 1995; Ellis et al., 2002). For present purposes the most pertinent of these associated behaviours is that of verbal statements and how these are used in an assertive fashion to acquire or promote favourable impressions. Of particular interest is how managers 'frame' their accounts in a fashion that causes others to accept one meaning over another (cf. Gardner and Avolio, 1998). This involves highlighting and downplaying various aspects of the same situation in an attempt to emphasise one interpretation as 'real' over other possible interpretations (Bean and Hamilton, 2006). Framing, as such, involves shaping the general perspectives upon which information is presented and interpreted; much like how photographers would choose when and how to take their photos in order to make the audience see the world from their perspective (Fairhurst and Sarr, 1996).

\section{Research method and theoretical framework}

The research presented here is based on the analysis of transcripts from in-depth interviews with innovation champions originating from a study of innovation in the 
Facilities Management (FM) sector, conducted 2003-2005. FM represents one of the fastest growing sectors in real estate and construction and has become an important subject for research and academic study. The original research used a multiple case study design to study innovative practices in eleven companies and drew on a variety of data collecting techniques. The main aim of the study was, in line with Rogers' (2003) model of innovation diffusion, to investigate the means by which innovations are initiated and subsequently diffused across the FM sector. The cases were chosen following a wide-ranging invitation to organisations associated with the British Institute of Facilities Management (BIFM). Companies that by their own accounts were, or had recently been, involved in a successful innovation process were invited to take part. Included in the final sample were companies falling into the following categories: FM contractors, in-house FM teams, FM suppliers and FM consultants. The findings from the original research project have previously been published in (Cardellino and Finch 2006a; Cardellino and Finch 2006b).

As part of the original data gathering exercise key actors who had been active in the realisation of the innovation were interviewed at length. In-depth interviews were conducted with the specific innovation champion in seven out of the eleven organisations. These individuals had either identified themselves as such or were identified by other respondents within the organisation as having had the role. In one of the cases two individuals were considered to have shared the role of champion. The interviews followed a semi-structured approach allowing the respondents to speak freely about the innovation process from origin of idea through 
implementation to performance in use. The interviews were recorded and transcribed in verbatim. All eight interviewees held strong views about innovation. They were in no doubt about the importance to their respective businesses of innovation in general and the targeted innovation in particular. Furthermore, they all aired similar views vis-à-vis their own importance in the development of the innovation. Thus, the transcripts were deemed as very suitable for studying the way in which innovation champions interpret, justify and frame the diffusion of innovation in their own organisations.

\section{Seven innovations and their champions}

The companies that the innovation champions represent can be divided into two broad categories; external FM service providers and in-house FM providers. Whilst not critical to the study at hand, this distinction is important as it allows for a better contextual understanding. The relationship between the FM task and the core business of the organisation can in this way better be taken into consideration. In particular, it allows for a more nuanced analysis of the rhetoric the innovation champions used in describing the innovation.

Short descriptions of the innovations, the types of company in which they were developed and the position held by the innovation champion are provided in Table 1 . Most of the organisations that took part in the study openly admitted that the idea itself was not new. The innovative aspects of the endeavour they claimed lay in the 
way the technology/procedure was adapted to suit their own particular context. In common across the seven case studies was that whilst most of the innovations were non-technological in nature, they were dependant on technology to enable them to develop. Usually this involved further refinement of existing of-the-shelf technology that had been tried and tested in other areas.

Table 1: seven innovations and their champions

\section{Theoretical framework for analysis}

According to neo-institutional theories, justifications have their origin in, and are actively developed from, commonly accepted opinions that are generally believed and taken for granted - endoxa. Such commonly held assumptions are referred to elsewhere as for example: 'myths' (Meyer and Rowan, 1977), 'dominant logics' (Prahalad and Bettis, 1986), ‘paradigms’ (Sheldon, 1980), ‘institutions’ (Barley and Tolbert, 1997) and ‘industry recipes’ (Spender, 1989). Managers aiming to justify the adoption and diffusion of an innovation would aim to be consistent with the commonly held assumptions of the target audience (Suchman, 1995). Thus, the verbal element of impression management strategies would if successfully deployed be perceived to be congruent with the audience's definition of the situation (Gardner and Martinko, 1988). 
Social scientists have, over the years, offered a number of frameworks for analysing how actions are legitimised and justified and an extensive literature exists on the topic (e.g. Green, 2004; Suddaby and Greenwood, 2005). Similarly much research has been undertaken studying impression management techniques in various interview situations (e.g. Gilmore and Ferris, 1989; Ellis et al., 2002). In order to investigate the verbal statements provided by the innovation champions we have chosen to go back to basics and use classic rhetoric and its three primary forms of persuasive appeals (pisteis) ethos, logos and pathos.

These three primary forms of persuasive appeal, each impact on different aspects of the human mind-set: 'ethos' appeals to the individual's character; 'pathos' appeals to emotions; and 'logos' appeals to reason. Aristotle argued that these three artistic modes of persuasion were essential in making a persuasive argument. The argument should: awaken emotion (pathos) in the audience so as to induce them to make the judgement desired; illustrate the probability of what was said by logical argument (logos); and present the character (ethos) of the speaker in a favourable light (Aristotle, 1991). Despite criticisms of the context specificity of Aristotle’s original work, contemporary rhetorical theories are fairly unanimous in drawing on these three main types of appeal (cf. Bizzell and Hertzberg, 1990; Green, 2004; Herrick, 2004). Space prevents more than a brief introduction; for more detailed descriptions see for example Aristotle (1982; 1991), Bizzell and Hertzberg (1990) and Herrick (2004). 
The Pathos appeal impacts on the emotions of the audience. As such, it may well be very passionate in its form. Pathos justifications are used to justify a particular cause of action based in no small way on the listener's sense of self-interest. Further, they would seek to target issues that are likely to illicit an immediate response from the audience. This could, for example, take the form of appeals associated with fear and greed, or risks and opportunities. Usually this type of justification is made in an attempt to instigate associations and behaviour directed away from the status quo. Pathos appeals are initially very persuasive, but justifications based on these kinds of emotional appeals are often unsustainable.

Logos appeals are concerned with reason and affect the logical part of the mind. Justifications of this kind are therefore commonly directed at assumptions concerning efficiency and effectiveness of actions. Hence, the listener may be triggered into thinking along the lines of means and ends. In consequence, a logos justification might not be immediately appealing, yet if accepted could prove to be more sustainable than a pathos justification.

An Ethos justification appeals to moral or ethical sensibilities and hence targets judgements of what could be considered as 'the right thing to do'. The fundamental aim is to project the character of the speaker and those he represents in a favourable light. Invoking trust is a key motive. Action is justified through appeals to socially accepted norms. Focus is more on social and collective interests than on the interests 
of the individual. It is not uncommon that effective ethos appeals are taken to be synonymous with what is 'right' and what is 'good'.

\section{Analysis approach}

Detailed coding and subsequent analysis of the interview transcripts was undertaken in two main stages. The first stage focused on distinguishing the segments in which the interviewees spoke about various events, actions and decisions coupled with the innovation. The identified segments were then divided into three chronological categories allowing focus to be given to the innovation champions' accounts of: (a) what took place before the innovation; (b) how the innovation was adopted and implemented; and (c) how the innovation performs in use.

The second stage focused on the latent content of each of the identified segments. In particular, this stage was concerned with the presence of justifications and legitimising language in the form of the three persuasive appeals. Initially, a forced approach to coding was used, i.e. if more than one appeal was present in the particular segment a decision was taken regarding which one was most prominent. The subsequent analysis provided a rough picture of the sequences in which the three appeals were used. It also showed how the interviewees changed between appeals depending on the phase of the diffusion process that was being discussed. However, it was clear that focusing solely on the dominant appeals omitted important subtleties in the arguments that were being conveyed. A second round of 
coding was therefore undertaken in which combinations of stronger (dominant) and complementary weaker appeals were identified. In order to ascertain reliability, this round of coding was performed separately by the two authors. The level of congruence between the two sets of coding was sufficiently high to ensure a degree of confidence. Segments where opinions differed were revisited until consensus was reached on the types of appeals that were present. This second round of coding allowed for a more nuanced representation of the three appeals to be taken into consideration, especially how they are intertwined toward persuasive ends. The patterns identified across all the interviews were compared and cross-referenced in order to identify the existence, or non-existence, of common rhetorical strategies and sequences.

\section{Interpreting interview data through the lens of persuasive appeals}

The findings are presented in four sections below. The first two sections 'purpose of the innovation' and 'the origin of the idea' are both concerned with what took place before the innovation. Combining the two provides a picture of how the innovation champions justified the rationale behind the innovation and why it was implemented. The third section 'innovation commitment' discusses how the interviewees described the actual implementation of the innovation. Finally, the fourth section 'innovation outcome' exemplifies how they chose to describe the way the innovation was diffused and how successful it could be considered to be. 
The presentation is descriptive in nature. Each of the four sections has an introduction outlining the common issues that the innovation champions chose to highlight and how they framed their arguments. In support, examples are then provided from a selection of the cases. Space limitations restrict the reproduction of lengthy extracts. Descriptions are therefore provided of how the arguments unfolded and excerpts from the transcripts are only used for illustrative purposes. As the analysis targeted the use of impression management tactics and rhetorical strategies by the respondents the descriptions are not to be read as definite accounts of how the innovations diffused. Each of the four sections is concluded with a summary of how arguments and justifications have been framed through the use of rhetorical sequences, together with further descriptions and plausible explanations thereof.

\section{Purpose of the innovation}

The parts of the transcripts where the interviewees described the innovation and its specific purpose or use were dominated by references to the provision of more efficient services and the ultimate goal of retaining customers. Explanations were commonly provided along the lines of the organisation engaging in a constant search for more efficient ways of delivering their services. As such it was argued that the innovations enabled the organisations to retain contracts by providing their clients with more efficient modes of working. Whilst the interest of the company was portrayed as important, the answers were consistently given against the backcloth of the main beneficiary being the client. 
Two patterns for the framing of the purpose of the innovation emerged. The first, and dominant, pattern uses pathos appeals backed by logos appeals in justifying the innovation. In the second pattern the justifications are based predominantly on ethos appeals backed up with slightly weaker logos appeals. The pathos-logos approach is well illustrated by Case 4 and the ethos approach is illustrated by Case 2 .

The innovation champion in Case 4 describes his innovation as a 'passport to success'. The main purpose of the innovation was to come to grips with the low skill levels and high turnover of the personnel:

"In traditional cleaning there was high turnover. There was no real support between the manager and the staff... When we are training staff we tend to do it by telling them what to do, but when you go to the workplace and observe what they do, they do it their way. So to get people to be productive they need to clean intelligently. I don't think they were doing all that good.”

He then goes on to argue that the implementation of the innovation was important because it focuses on both commercial and social interests. In his opinion the innovation is beneficial for the client as it addresses the issues of safety and security by improving the staff's knowledge of these issues through proper training. The basic underlying argument is that access to this 'passport' allows the staff to be more effective in their work. 
Case 2 presents the strongest presence of ethos appeals in the justification of the innovation. The two innovation champions present their innovation as the only way forward as it represents the 'culture' of the company and facilitates practices based on honesty and transparency:

"This system represents our culture and it is not the starting point, but the end point is what we have derived from it... The new system epitomises our values and the way that we perform, it is the crystallisation of what the company is".

and:

"This commitment removes any concern about dubious charging practices and we believe it establishes the best possible platform for long term relationships based on honesty and consistency of quality delivery”.

These ethos appeals are then followed by slightly weaker justifications as they go on to explain that when providing services the company wants to present the client with a better understanding of the service and how their money is being used.

The difference between the two identified patterns for describing the purpose of the innovation lies in the initial explanations given by the interviewees. In the first category pathos appeals were chosen, e.g. the facilities managers would have been 
failing their clients unless the innovation was implemented. In the second category, ethos appeals were used in the way of portraying the innovation as the right thing to do, e.g. 'the new system epitomises our values'. In our sample, the pathos-logos approach was the most common. All interviewees had a common tendency to turn to logos justifications towards the end of the narrative by highlighting that it was a more effective and efficient way of delivering services. As such the descriptions were framed to uphold the beliefs that the organisation works meticulously to achieve stated goals.

\section{The origin of the idea}

The innovation champions were asked to recall the origin of the innovation and to describe and explain how the idea originated and its original stimuli. A similar pattern appeared in 6 of the 7 cases. The interviewees stated that the origin of the idea was, in one way or another, based on a fear of loss. In the case of external FM providers this fear was chiefly concerned with the fear of losing the contract. The explanations given were that if they did not come up with innovative ideas they would not get the contract with the client renewed. For the in-house service providers similar arguments were used, but with the emphasis put on the loss of internal productivity. The pattern that emerged was that of justifying the innovation drawing on pathos arguments supported by weaker appeals, usually logos. 
In Case 4 the innovation champion was at first very short in his justification explaining that the lack of professionalism and the need to increase people's skills and productivity within the sector had stimulated the initial idea. This appeal was grounded in the fear that they were going to lose business if they were not able to reduce costs. He then switches to a logos appeal and goes on to explain that:

"In cleaning, the labour cost is the highest for the business. So if everybody pays the same the only way to compete is to be more productive".

The appropriate route of action, i.e. increasing people's skills and productivity, was thus justified based on arguments surrounding a more efficient delivery of the service. In similar fashion, the innovation champion in Case 7 justified the origin of the new idea as a response to the risk that the system could fail at any time. Reliable systems were needed to ensure that the client organisation could work 24 hours a day.

The innovation champion in Case 6 used a slightly different pathos plea in appealing to the necessity of being able to 'achieve customer satisfaction' in the workplace. How the customer (in this case the company's employees) perceived the workplace was the major concern and prompted the idea. However, a little later he changes his line of argument and points towards the appointment of a new CEO as triggering the 
innovation to arise. The CEO drove the idea forward and appointed the interviewee as the dedicated innovation champion:

"The chairman, the chief executive said this satisfaction is not good enough and he was determined to remove dissatisfaction [within the company]."

With the exception of the two interviewees in case 2, the innovation champions all made use of pathos appeals in their accounts of the origins of the innovations. In most of the cases the risk of losing business was the initial explanation of what had encouraged the development of the innovation. These appeals are primarily pleas to the emotions of the person listening and are in most cases immediately acceptable. Logos appeals were then used to justify and reinforce the idea that the innovation would help the company to differentiate itself from its competitors or better adapt to the wishes of the parent company.

\section{Innovation commitment}

This third section looks at the parts of the interviews that targeted the implementation period of the innovation. The innovation champions were asked about the commitment to innovate, the actions taken and the main experienced barriers for the implementation of the innovation. It is noteworthy that the interviewees all referred to facilities managers as being sceptical to new ideas that involve changing the way they work. This was something they considered to be universally true across the discipline. Thus, their own staff was presented as the 
main barrier to the successful adoption of the innovation. The explanations given were those of top-down models of business strategy - senior management decides and the users are forced to adapt. Naturally, there were slight variations between the in-house and the external FM providers. However, the story most consistently portrayed was that the users were informed of the changes once decision makers in the client organisation decided to proceed. Workshops and training to inform users about the changes were provided, but not before the decision to go ahead had been taken. The main criterion used to justify implementation was client acceptance. Not in any of the cases was it linked to the users' acceptance of the idea. The pattern that appears is one of mixing ethos and logos justifications. The innovation champions were more inclined to initially use ethos justifications, eventually followed by slightly stronger logos appeals.

In Case 1 the innovation champion starts by explaining that they committed to the innovation after the contract had been signed as they had explicitly committed to do so. However, this ethos appeal is followed up by more commercially oriented explanations of the decision to innovate. These revolve around the desire to provide visibility to their client that the company is both credible and efficient. The innovation champion argues that it is sometimes difficult for them to demonstrate what they do as they are a managerial company. The main barrier to the innovation is believed to be the facilities manager's acceptance of the innovation. This was further justified through underlining the experienced difficulty of making facilities managers understand the usefulness of the innovation: 
"What happens is that facilities managers feel they have experience, but some of their experience is not very good...There was some resistance from the facilities managers' point of view on why they needed to use this. It takes time to make them understand the benefit of using this system".

However, like the others, he then carries on by explaining that the important thing after all is the client and them understanding the value of the innovation.

The innovation champion in Case 3 is convinced the innovation was the right thing to do. The employees had no say regarding the acceptance of the new idea. The story told is one of strong leadership on behalf of the champion. There was little scope for anyone to object.

"From the situation of the workforce that was transferring we got permission to get them together as a group and they were told this is the way we are going to do work and we will train you."

Ultimately, the interviewee explained that the innovation had been a success as the company had managed to obtain the fulfilment of the users' needs.

In summary, the interviewees all told the story of how they managed to strike a balance between what is unique and beneficial for the client and, at the same time, 
achieving a fit with the business strategy of their own organisation. They draw on a combination of ethos and logos appeals with a slight tendency to emphasise the logos justifications. They consistently portray their staff as the key barriers to the implementation of the innovation. However, ultimately the benefits exceed the distress, the employees fall into line and the customer is the main beneficiary.

\section{Innovation outcome}

The latter parts of the interviews focused on the perceived success of the innovation and the way in which it was measured. Financial performance was consistently described as important and included aspects such as profitability, the attainment of cost targets and the degree to which costs were reduced. However, this was without fail qualified by other performance criteria such as quality, value added and competitive differentiation. In the majority of cases, it was made clear that the acceptance of the innovation had not been straightforward; frequent appeals were made for the difficulty of changing working practices. Still, according to the respondents, the innovations had gradually become accepted as part of the 'normal way of working'. All the innovation champions eventually linked the success of the innovation to the fulfilment of client needs. The dominant pattern was one of using ethos appeals, as exemplified by cases 1 and 5 .

The champion in Case 1 is very clear in his evaluation of the innovation and its usefulness. It is described as beneficial for the own company in terms of ensuring 
the retaining of the contract. But much more emphasis is given to the benefits it has generated for the client organisation which is described as struggling in other areas of operation.

"Our approach with the use of this technology has differentiated us from the competition and has provided the client with the confidence to maintain our services even though they are losing financially in their core business.

In Case 5, the innovation champion takes the argument one step further and claims that the innovation enabled them to go beyond merely fulfilling the client's present needs. It allowed them to help facilitate the clients' future development:

“We are developing, working with the clients to understand the users' needs. Surely they don't know what they want their building to do. So, using the tool allows them to deliver a building that will more efficiently achieve their real needs. It is not only fulfilling clients' needs but developing them to get a better performance from the building".

In summary, the innovation champions chose to describe the success of their innovation in two stages. The first stage gravitated towards profits for the own company. These could be in the form of more efficient modes of working and, in many cases, the ability to secure future work. The second stage invariably drew on 
ethos appeals and dealt with the fulfilment of clients' needs and how the clients are benefiting from the innovation in question.

\section{Discussion}

The notion of pro-innovation bias in the research literature was rehearsed in the introduction. The original research upon which the current study is based could also be considered guilty of a similar bias. The method of sending out an open invitation to companies to subject their working procedures to investigation almost certainly results in a biased sample of volunteers. Managers are more likely to broadcast the details of their actions if they are perceived to have been successful (Strang and Macy, 2001). This is a self-promotion mechanism, but also serves to project favourable images of the organisation within key constituencies.

Credibility, external and internal, is of great importance both for the individual and the organisation. The innovation champions' descriptions of their innovations and their accounts of the diffusion process should, thus, be considered to be constituent parts of a wider discourse that encompasses the relationship between environment, organisation and organisational processes. The symbolic role of managing (cf. Pfeffer, 1981) cannot be disregarded. Management not only directs organisational activities, they also foster the beliefs among the organisational audiences that it does so. Managers accordingly strive to elucidate their efficacy even in contexts where control is more than elusive. Effective impression management tactics is a key tool 
they can utilise in attempts to achieve individual and organisational legitimacy. The findings suggest that this extends into the academic interview situation. It does, however, deserve to be noted that managers, and in this case innovation champions, not necessarily set out to be manipulative. Continuous processes of self-interest, self-perception, self-deception and wishful thinking (i.e. personalisation) are likely to change the means with which they identify themselves with legitimising narratives that support their position. Furthermore, impression management is an interactive process (cf. Ginzel et al., 2004). The interview questions provide the cues on which the interviewee chooses which perceptions he/she wishes to promote.

Framing descriptions of innovation diffusion

The innovation champions in the study represented organisations of differing sizes and operational directions. Some were part of large multinational corporations whilst others represented specialised FM providers. As could be expected the contents of their descriptions therefore differed. However, it is how they framed their arguments and how actions and decisions were justified that has been the focus of this study. As such an attempt has been made to deconstruct how rhetorical strategies manifest themselves in the interviews.

The findings point towards great similarities in the rhetorical strategies of the eight innovation champions. Their accounts are telling in how they draw on the similar 
combinations and sequences of persuasive appeals when framing the messages that they want to get across. They all had in common that they initially focused on easily recognisable and acceptable arguments for change, drawing heavily on pathos appeals. Justifications such as these tend to grab the attention and affect the imagination of the listener and instigate associations and behaviour directed away from the status quo. The instigation of the innovation was portrayed as a response to a fear of losing a contract or internal productivity. Framing their descriptions in this fashion provides for arguments that are instantly acceptable for listeners with some insight into the context discussed. Certainly they are more readily convincing than explanations along the line of 'it just happened'.

Yet, although initially very persuasive, justifications based on pathos appeals often seem unable to sustain their persuasiveness. The interviewees, thus, followed up the initial pathos appeals with logos justifications allowing for a greater and more sustained acceptance of the arguments put forward. In particular, using justifications based on efficiency and effectiveness generates readily acceptable explanations for the undertaking at hand (cf. Colomy, 1998). Furthermore, it increases the likelihood for the acceptance of links between decisions and behaviours and effective outcomes. Efficiency and effectiveness are powerful arguments that managers aver to generate and sustain support for the undertaking at hand.

In all cases the innovations were ultimately justified through ethos appeals describing how clients have benefited. Drawing on these kind of descriptions of 
long-term gains for others and notions of relative 'goodness' removes the argument from the individual allowing for a sustained acceptance of the accounts given. If successful the audience will see the organisation as valuable and worthy of support as it acts on collected valued purposes in a proper and adequate manner.

In summary, the similarities in how the descriptions were framed are telling. In particular how the interviewees draw on different combinations of appeals in relation to various stages of the diffusion process in order to generate acceptance. Initially the accounts focus on easily recognisable and acceptable arguments for change. The implementation of the change is then justified through arguments targeting efficiency and effectiveness. Finally, the whole endeavour is justified through describing how both the company and its clients have benefited.

\section{Self promotion}

The respondents shared similar self-promotion strategies, the most striking of which being the portrayal of the own staff as the key barriers to the innovation. Such statements serve to enhance character attributions such as the competence of the interviewee (Ellis et al., 2002). They also serve to portray the image of the individual as being capable of successfully circumventing barriers that impede progress (Ginzel et al., 2004). Anchoring the argument in the common perception 
within the sector that facility managers are reluctant to change (cf. Finch, 2004) makes the argument easily acceptable and there is little reason to question the extent to which the barrier was really there.

\section{Limitations}

We readily acknowledge that there are limitations inherent in this kind of study. Our empirical examples draw from a limited number of interviews with innovation champions working in FM. We cannot claim statistical significance to our sample. However, the purpose of the study was to investigate the occurrence of impression management strategies in the accounts of innovation champions. The transcripts we have analysed represent the accounts of managers, in seven very different organisations, who have been identified as having championed a successfully implemented innovation. The presentation of the findings is useful in showing how the three persuasive appeals are drawn upon and combined to frame the justifications of actions and decisions taken during various phases of the innovations' development. In particular it has shown how looking at data through the lens of rhetoric could help further our understanding of innovation diffusion. The deliberate framing of persuasive language to legitimise an innovation through the creation of congruence with the commonly held assumptions of the target audience can be identified and deconstructed. 


\section{Conclusion}

Managers' accounts of innovation exist within and reflect a much wider discourse that defines inter and intra- organisational contexts. Innovation champion's actions at the time undoubtedly make a substantial difference in the extent to which organisational activities are perceived as desirable, proper and appropriate within the given context. However, their ability and desire to continuously justify and legitimise the change should not be overlooked. The need for sustained justification of the innovation is very likely to affect retrospective accounts, including academic interviews. This study has analysed the verbal statements provided by innovation champions in research interviews. A compelling argument emerges of how a greater appreciation of the way rhetorical strategies manifest themselves in data collected through interviews could serve to be very useful in researching innovation. In particular, it could help in the unravelling of the, at times, subtle differences between the objective and subjective dimensions of innovation.

Particular attention has been given to the importance of rhetorical underpinnings of change and how rhetorical strategies are used for the purpose of legitimisation. The study is limited in scope but it can nevertheless be concluded that there is value in not accepting all the statements made by innovation champions or key personnel as established factually correct accounts of history. Indeed, too heavy a reliance on the accounts given by key respondents could be a rather hazardous strategy unless 
proper recognition is given to context and motivation. Using a rhetorical lens in the study of innovations allows for a critical examination of the relationships between justifications and diffusion hence alleviating some of these concerns. It also allows for blatant impression management strategies to be ignored.

It cannot be stressed enough that managers use language as an important tool and their rhetorical strategies have consequences. Rhetorical strategies draw on the meaning systems that underpin institutions. It is, therefore, suggested that the discourse justifying change may construct the world in such a way that the outcomes of the change conform to its description. Examining the link between the rhetoric of a new practice and the reality of that practice therefore seems like a fruitful avenue for future research. This study has focused on affirmative rhetoric that has sought to justify actions. The findings point at significant similarities in the framing of justifications. Further research should be undertaken to investigate whether such similarities also are present in samples from different interviewee populations and other organisational contexts, e.g. temporary project organisations. Finally, the three persuasive appeals, pathos, logos and ethos, form the rationality underlying both the adoption and rejection of change. Further studies should therefore also target the types and sequences of persuasive appeals that are used by those who oppose to change as well as those who have partaken in failed attempts at innovation. This would allow for comparative analyses and would do much to further our understanding of the relative significance of language in innovation diffusion research. 


\section{References}

Abrahamson, E. (1991) Managerial fads and fashions: the diffusion and rejection of innovations. Academy of Management Review, 16(3), 586-612.

Akrich, M., Callon, M. and Latour, B. (2002) The key to success in innovation part II: The art of choosing good spokespersons (Translated by A. Monaghan). International Journal of Innovation Management, 6(2), 207-225.

Anderson, N., de Dreu, C.K.W. and Nijstad, B.A. (2004) The routinization of innovation research: a constructively critical review of the state-of-the-science. Journal of Organizational Behavior, 25, 147-173.

Aristotle. (1982) The Art of Rhetoric. (Translated by J. H. Freese). Loeb Classical Library, Harvard University Press, Cambridge, MA.

Aristotle. (1991) On Rhetoric: A Theory of Civic Discourse. (Translated by G. A. Kennedy). Oxford University Press, Oxford.

Arndt, M. and Bigelow, B. (2000) Presenting structural innovation in an institutional environment: Hospitals' use of impression management. Administrative Science Quarterly, 45(2000), 494-522. 
Ashforth, B.E. and Gibbs, B.W. (1990) The double edge of organizational legitimation. Organization Science, 1(2), 177-194.

Barley, S.R. and Tolbert, P.S. (1997) Institutionalization and Structuration: Studying the Links between Action and Institution. Organization Studies, 18(1), 93-117.

Barlow, J. (2000). Innovation and learning in complex offshore construction projects. Research Policy, 29(7-8), 973-989.

Bean, C.J. and Hamilton, F.E. (2006) Leader framing and follower sensemaking: response to downsizing in the brave new workplace. Human Relations, 59(3), 321349.

Bizzell, P. and Herzberg, B. (eds) (1990) The Rhetorical Tradition: Readings from Classical Times to the Present. Bedford Books of St. Martin’s Press, Boston.

Bozemann, D.P. and Kacmar, K.M. (1997) A cybernetic model of impression management processes in organizations. Organizational Behaviour and Human Decision Processes, 69(1), 9-30. 
Briscoe, G.H., Dainty, A.R.J., Millett, S.J. and Neale, R.H. (2004) Client-led strategies for construction supply chain improvement. Construction Management and Economics, 22(2), 193-201.

Cardellino, P. and Finch, E. (2006a) Evidence of Systematic Approaches to Innovation in Facilities Management, Journal of Facilities Management, 4(3), 150166.

Cardellino, P. and Finch, E. (2006b) Mapping IT innovation in Facilities Management. Electronic Journal of Information Technology in Construction, 11, 673-684.

Colomy, P. (1998) Neofunctionalism and Neoinstitutionalism: Human Agency and Interest in Institutional Change. Sociological Forum, 13(2), 265-300.

Dainty, A (2007) A review and critique of construction management research methods. Construction Management and Economics 25th Anniversary Conference. Reading, July 16-18.

Dulaimi, M.F., Nepal, M.P. and Park, M. (2005) A hierarchical structural model of assessing innovation and project performance. Construction Management and Economics, 23(6), 565-577. 
Ellis, A.P.J., West, B.J., Ryan, A.M. and DeShon, R.P. (2002) The use of impression management tactics in structured interviews: A function of question type. Journal of Applied Psychology, 87(6), 1200-1208.

Elsbach, K.D. (1994) Managing organizational legitimacy in the California cattle industry: the construction and effectiveness of verbal accounts. Administrative Science Quarterly, 39(1994), 57-88.

Fairhurst, G. T., \& Sarr, R. A. 1996. The art of framing: Managing the language of leadership. Jossey-Bass, San Francisco.

Finch, E. (2004) Facilities Management. In D.Clements-Croome (ed.) Intelligent Buildings: Design, Management and Operation. Thomas Telford, London.

Fiss, P.C. and Zajac, E.J. (2006) The symbolic management of strategic change: sensegiving via framing and decoupling. Academy of Management Journal, 49(6), 1173-1193.

Gardner, W.L. and Avolio, B.J. (1988) The charismatic relationship: A dramaturgical perspective. Academy of Management Review, 23(1), 32-58.

Gardner, W.L. and Martinko, M.J. (1988) Impression management in organizations. Journal of Management, 14(2), 321-338. 
Gilmore, D.C. and Ferris, G.R. (1989) The effects of applicant impression management tactics on interviewer judgements. Journal of Management, 15(4), 557564.

Ginzel, L.E., Kramer, R.M. and Sutton, R.I. (2004) Organizational Impression Management as a Reciprocal Influence Process: The Neglected Role of the Organizational Audience. In M.J. Hatch and M. Schultz (eds.) Organizational Identity. Oxford Management Readers, Oxford.

Green, S.E. (2004) A rhetorical theory of diffusion. Academy of Management Review, 29(4), 653-669.

Gray, C. and Davies, R.J. (2007) Perspectives on experiences of innovation: the development of an assessment methodology appropriate to construction project organizations. Construction Management and Economics, 25(12), 1251-1268.

Herrick, J.A. (2004) The History and Theory of Rhetoric: An Introduction (3rd ed.). Allyn and Bacon, Boston.

Howell, J.M. and Higgins, C.A. (1990) Champions of Technological Innovation. Administrative Science Quarterly, 35(1990), 317-341. 
Isabella, L.A. (1990) Evolving interpretations as a change unfolds: how managers construe key organizational events. Academy of Management Journal, 33(1), 7-41.

Ivory, C. (2005) The cult of customer responsiveness: is design innovation the price of a client-focused construction industry?. Construction Management and Economics, 23 (8), 861-870.

Macy, M.W. (1997) Identity, interest and emergent rationality. Rationality and Society, 9(4), 427-448.

Meyer, J.W. and Rowan, B. (1977) Institutionalized organizations: Formal structure as myth and ceremony. The American Journal of Sociology, 83(2), 340-363.

Mudrak, T., van Wagenberg, A. and Wubben, E. (2005) Innovation process and innovativeness of facility management organizations. Facilities, 23(3/4), 103-118.,

Nam, C.H. and Tatum, C.B. (1997) Leaders and champions for construction innovation. Construction Management and Economics, 15(3), 259-270.

Nelson, R.R., Peterhansl, A. and Sampat, B. (2004) Why and how innovations get adopted: a tale of four models. Industrial and Corporate Change, 13(5), 679-699. 
O’Neill, H.M., Pouder, R.W. and Buchholtz, A.K. (1998) Patterns in the diffusion of strategies across organizations: insights from the innovation diffusion literature. Academy of Management Review, 23(1), 98-114.

Peansupap, V. and Walker, D.H.T. (2006) Innovation diffusion at the implementation stage of a construction project: a case study of information communication technology. Construction Management and Economics, 24(March), 321-332

Pfeffer, J. (1981) Management as symbolic action: The creation and maintenance of organizational paradigms. Research in Organizational Behaviour, 3, 1-52.

Poole. M.S. and Van de Ven, A.H. (1989) Towards a general theory of innovation. In A.H. Van de Ven, H.L. Angle and M.S. Poole (eds), Research on the Management of Innovation: The Minnesota Studies. Harper and Row, New York, pp. 637-662.

Prahalad, C.K. and Bettis, R.A. (1986) The dominant logic: a new linkage between diversity and performance. Strategic Management Journal, 7, 485-502.

Rogers, E. M. (2003) Diffusion of innovations. $5^{\text {th }}$ Edn. Free Press, New York. 
Rouleau, L. (2005) Micro-practices of strategic sensemaking and sensegiving: How middle managers interpret and sell change every day. Journal of Management Studies, 42(7), 1413-1441.

Salancik, G.R. and Meindl, J.R. (1984) Corporate attributions as strategic illusions of management control. Administrative Science Quarterly, 29(1984), 238-254.

Sharma, A. (1999). Central dilemmas of managing innovation in large firms. California Management Review, 41(3), 146-164.

Sheldon, A. (1980) Organizational paradigms: A theory of organizational change. Organizational Dynamics, 8(3), 61-80.

Slaughter, E.S. (1998) Models for construction innovation, Journal of Construction Engineering and Management, 124(3), 226-231.

Spender, J.-C. (1989) Industry Recipes: The Nature and Sources of Managerial Judgement. Blackwell, Oxford.

Staw, B.M., McKechnie, P.I. and Puffer, S.M. (1983) The justification of organizational performance. Administrative Science Quarterly, 28(1983), 582-600. 
Strang, D. and Macy, M.W. (2001) In search of excellence: fads, success stories, and adaptive emulation. American Journal of Sociology, 107(1), 147-182.

Suchman, M. (1995) Managing legitimacy: strategic and institutional approaches. Academy of Management Review, 20(3), 571-610.

Suddaby, R. and Greenwood, R. (2005) Rhetorical strategies of change. Administrative Science Quarterly, 50(2005), 35-67.

Tatum, C.B. (1984) What prompts construction innovation?. Journal of Construction Engineering and Management, 110(3), 311-323.

Van-de-Ven, A., Polley, D., Garud, R. and Venkataraman, S. (1999) The Innovation Journey. Oxford University Press, New York.

Wayne, S.J. and Liden, R.C. (1995) Effects of impression management on performance ratings: a longitudinal study. Academy of Management Journal, 38(1), 232-60.

Widen, K. and Hansson, B. (2007) Diffusion characteristics of private sector financed innovation in Sweden. Construction Management and Economics, 25(5), 467-475. 
Winch, G. (1998) Zephyrs of creative destruction: understanding the management of innovation in construction. Building Research and Information, 26(4), 268-279.

Wolfe, R.A. (1994) Organizational innovation: review, critique and suggested research directions. Journal of Management Studies, 31(3), 405-431.

Whyte, J. (2003) Innovation and users: virtual reality in the construction sector. Construction Management and Economics, 21(6), 555-572.

Table 1 Seven innovations and their champions

Case General description of company and innovation Innovation champion

External FM providers

Case 1 A management company established to provide an integrated range of The identified innovation products in facilities management, project management and facilities consultancy. The innovation consisted of the development of a health and safety management and audit tool. The ultimate aim was to combine champion is the managing director of the company. the tool with the further development of technology software, which would allow facilities managers to work in a more systematic manner.

Case 2 The company among other things provides project delivery, building maintenance and relocation management services to their clients. The innovation involved the development of an electronic management portal. The overall aim with the portal was to enable a more efficient and collaborative way of working that would not impede the specific statutory and operational requirements of clients.

Case 3 A company that provides construction, maintenance, joinery and mechanical services. The innovation in question was the development of a system allowing for the provision of a partnered full open book accounting service.

Case 4 The company provides cleaning services to a wide range of clients. The innovation involved the development of an internal 'passport scheme' and the employment of a local college to hold a weekly English class for staff. In particular, focus was put on getting the blue collar workers to take pride and responsibility for the work they undertake.

In-house FM

Case 5 A large company active in the defence sector. The innovation consisted

The innovation champion is the 
of the development of a 'facilities whole life cost model' that estimates the life of the building components. In particular, the individual

components impact on the overall life cycle of the building from the empty site through to occupancy, demolition and beyond. The tool takes into account the sustainability and cost of each component and from this information it ascertains the future maintenance costs.

Case 6 The company provides communication solutions serving customers all over the world. The innovation consists of the development and

implementation of a survey tool that investigates employees' perceived dissatisfaction of their working environment. The aim of the survey tool is to ascertain a thorough understanding of the employees' perception of their workplace and in this way provide a mechanism to redress feelings of dissatisfaction.

Case 7 A UK financial organization with a worldwide presence. The innovation consists of the development of a global engineering standard manual that can be implemented in any facility around the world. It makes use of a standard set of engineering terms on the subject of power management and data centre management to create the manuals. The aim was to create the same standard across the board to make the global facilities easier to operate. head of facilities management in one of the business areas.

The head of property services was assigned to champion the new idea.

The innovation champion is the global head of engineering within the FM group. 